\title{
Capacity to Address Social Needs Affects Primary Care Clinician Burnout
}

Alina Kung, MD, MS

Telly Cheung, $M D^{2}$

Margae Knox, MPH

Rachel Willard-Grace, MPH

Jodi Halpern, $M D, P b D^{1,4}$

J. Nwando Olayiwola, MD, MPH, FAAFP

Laura Gottlieb, MD, MPH ${ }^{6,7}$

'University of California Berkeley-UCSF

Joint Medical Program, Berkeley, California

${ }^{2}$ Albany Medical College, Albany,

New York

${ }^{3}$ University of California San Francisco, Center for Excellence in Primary Care,

San Francisco, California

${ }^{4}$ University of California Berkeley, School of Public Health, Berkeley, California

${ }^{5}$ Department of Family Medicine, Ohio State University College of Medicine, Columbus, Ohio

${ }^{6}$ University of California San Francisco, Department of Family and Community Medicine, San Francisco, California

${ }^{7}$ Social Interventions Research and Evaluation Network, San Francisco, California

Conflicts of interest: authors report none.

\section{CORRESPONDING AUTHOR}

Alina Kung, MD, MS

UCLA Department of Medicine

757 Westwood Plaza

Los Angeles, CA 90095

alina.kung@gmail.com

\begin{abstract}
PURPOSE Primary care clinicians disproportionately report symptoms of burnout, threatening workforce sustainability and quality of care. Recent surveys report that these symptoms are greater when clinicians perceive fewer clinic resources to address patients' social needs. We undertook this study to better understand the relationship between burnout and clinic capacity to address social needs.
\end{abstract}

METHODS We completed semistructured, in-person interviews and brief surveys with 29 primary care clinicians serving low-income populations. Interview and survey topics included burnout and clinic capacity to address social needs. We analyzed interviews using a modified grounded theory approach to qualitative research and used survey responses to contextualize our qualitative findings.

RESULTS Four key themes emerged from the interview analyses: (1) burnout can affect how clinicians evaluate their clinic's resources to address social needs, with clinicians reporting high emotional exhaustion perceiving low efficacy even in when such resources are available; (2) unmet social needs affect practice by influencing clinic flow, treatment planning, and clinician emotional wellness; (3) social services embedded in primary care clinics buffer against burnout by increasing efficiency, restoring clinicians' medical roles, and improving morale; and (4) clinicians view clinic-level interventions to address patients' social needs as a necessary but insufficient strategy to address burnout.

CONCLUSIONS Primary care clinicians described multiple pathways whereby increased clinic capacity to address patients' social needs mitigates burnout symptoms. These findings may inform burnout prevention strategies that strengthen the capacity to address patients' social needs in primary care clinical settings.

Ann Fam Med 2019;17:487-494. https://doi.org/10.1370/afm.2470

\section{INTRODUCTION}

$\mathrm{B}$ urnout remains a persistent problem among health care professionals. ${ }^{1-4}$ Higher levels of burnout symptoms are correlated with higher levels of depressive symptoms, ${ }^{5}$ less productivity ${ }_{1}^{6}$ reduced professional work effort, ${ }^{7}$ and greater intent to leave medical practice. ${ }^{8-11}$ Reduced work effort and increased turnover associated with burnout can disrupt continuity of care. Burnout is also expensive, with estimates of replacement costs exceeding $\$ 800,000$ per primary care physician. ${ }^{12}$ Manifestations of burnout such as emotional exhaustion, depersonalization, and low efficacy are also associated with decreased quality of care $^{13}$ and may exacerbate health inequities by disproportionately affecting clinicians working in lowresource settings. ${ }^{14,15}$ In these settings, the social determinants of health (SDH), including food, housing, and employment security, add to the complexity of providing care ${ }^{16}$ and contribute to increased clinician stress. ${ }^{14}$

Effective interventions are needed to combat rising rates of burnout and mitigate its consequences, particularly in primary care, where levels of reported burnout symptoms can be higher than those in other disciplines $s^{4,17,18}$ and more physicians report intent to reduce work hours or leave current practice. ${ }^{9}$ Interventions around burnout have included mindfulness, communication-related interventions, and scheduling changes. ${ }^{19}$ 
Recent meta-analyses show that these interventions have positive but modest effects. ${ }^{20,21}$ Given the relative intractability of clinician burnout in response to existing interventions, new intervention strategies are needed, especially in settings most vulnerable to burnout's consequences.

Recent studies have demonstrated direct or potential links between clinician burnout and the ability to address patients' social needs. ${ }^{22-26}$ One study showed that primary care clinicians reporting extreme stress were more likely to rate patients' social or financial issues as most relevant to patient complexity. ${ }^{22}$ Lower satisfaction with resources for treating complex patients has been associated with more symptoms of burnout ${ }^{23}$; conversely, practice preparedness to address social needs and ease of coordinating social services have been associated with greater clinician satisfaction. ${ }^{24}$ Two other studies also have shown that greater clinician perception of clinic capacity to address patients' social needs is significantly correlated with lower burnout. ${ }^{25,26}$

Despite this growing body of work linking low resources for meeting patients' social needs and clinician burnout, we know little about pathways connecting the two. Our main objective for this study was to understand how primary care clinicians conceptualize the relationship between burnout and capacity to address patients' social needs. In describing the constituents of that relationship, we also aimed to inform strategies for preventing burnout.

\section{METHODS}

\section{Study Design}

We used modified grounded theory and phenomenologic approaches to inform our study's interview guide creation, sampling strategy, coding, and analysis. ${ }^{27-29}$ First, we reviewed key literature on primary care clinician burnout and developed a semistructured interview guide (Supplemental Appendix, http:// www.annfammed.org/content/17/6/487/suppl/DC1). The interview guide was pilot tested with 4 full-time clinicians in settings serving low-income patients and refined in early interviews. Interview questions explored the relationships between primary care clinicians' workplace responsibilities and feelings of burnout, and their organization's capacity to address patients' social needs.

\section{Recruitment}

We recruited informants using clinician lists from a longitudinal study of primary care practices in the San Francisco Bay Area, previously described elsewhere. ${ }^{30}$ Clinicians were eligible for this study if they (1) worked at a site enrolled in the original primary care survey and had responded to the most recent survey wave (fielded November 2015) $;$ (2) were a physician, nurse practitioner, or physician assistant practicing primary care, ${ }_{i}$ and (3) worked 3 or more half-days of clinic a week.

We e-mailed 134 clinicians meeting eligibility requirements at 19 different outpatient clinics. Forty (30\%) responded affirmatively to the initial e-mail outreach, which is similar to response rates in other studies relying on e-mail outreach. ${ }^{31}$ We interviewed the first 29 respondents (representing 16 of 19 clinics) before we reached thematic saturation and ended recruitment.

\section{Data Collection}

Two authors trained in qualitative methods (A.K. and T.C.) conducted all study interviews, which involved audio-recorded, one-on-one, in-person conversations lasting 20 to 60 minutes. All interviews were conducted between June and August 2016. Informants provided verbal consent to participate before each interview. Study activities were approved by institutional review boards at the University of California San Francisco (institutional review board no. 11-08048) and the University of California Berkeley (study no. 1715).

\section{Survey Items}

All interviewees were asked to complete a brief questionnaire. The questionnaire included 2 validated, single-item measures on specific burnout domains: "I feel burned out from my work" (emotional exhaustion) and "I have become more callous since I took this job" (depersonalization). ${ }^{32}$ Participants also rated their agreement with the statement "My clinic has the resources, such as dedicated staff, community programs, resources or tools to address patients' social needs" on a scale from 1 to 10 , where higher score indicated greater agreement (SDH score). We collected completed questionnaires from 28 interviewees; 1 interviewee did not respond to these questions and was subsequently dropped from analyses.

\section{Data Analysis}

Each interview was professionally transcribed, reviewed for accuracy, and uploaded into the online qualitative analysis software Dedoose (SocioCultural Research Consultants, LLC). ${ }^{33}$ We used inductive and deductive processes ${ }^{34}$ for codebook development and thematic analysis. Two authors (A.K. and T.C.) first independently conducted line-by-line coding. Line codes were grouped into broader segment codes that were informed by key concepts in the literature review and discussed with experts in primary care and SDH. Segment codes were refined using the constant comparative method ${ }_{1}^{35}$ with ongoing discussion and rec- 
onciliation. Coders independently reviewed the first 20 transcripts to inform the final codebook, which a single coder (A.K.) then applied to all 29 transcripts. We then randomly selected 5 transcripts to be independently coded intercoder reliability was $90 \%$. All discrepancies were discussed and reconciled without need for a third reviewer.

\section{Thematic Development}

Clinicians discussed a broad range of themes related to their workplace, burnout, and experience addressing patients' social needs. Themes were distilled using an iterative process of concept mapping and code interpretation, with discussion involving all study authors. Responses were subsequently grouped by risk of emotional exhaustion and depersonalization, reanalyzed, and compared against original findings.

\section{RESULTS}

\section{Sample Characteristics}

Study participants included 22 physicians and 7 advanced care practitioners trained in primary care specialties, which closely mirrored the proportions in the recruitment pool (Table 1). As shown, participating clinicians varied in their responses to the single-item validated measures for emotional exhaustion and depersonalization and in their ratings of their clinic's capacity to address patients' social needs.

\section{Emergent Themes}

Four key themes emerged from the interview analyses. These themes, with exemplary quotations from clinicians, are detailed below.

\section{Burnout Can Affect Clinician Evaluation of Clinic Resources}

The way in which clinicians described clinic capacity to address social needs and its effect on their own efficacy varied by specific burnout phenotype (Table 2). Of note, the 17 clinicians with low to average emotional exhaustion and low to average depersonalization were more likely to express confidence in clinic resources to address social needs and maintain an individual sense of efficacy. The 8 clinicians with high emotional exhaustion but low to average depersonalization expressed doubt about the utility or contribution of social resources at their clinic more

\section{Table 1. Sample Characteristics}

\begin{tabular}{|c|c|c|}
\hline Characteristic & $\begin{array}{l}\text { Participants } \\
\text { (N = } 29 \text { Clinicians) }\end{array}$ & $\begin{array}{l}\text { Recruitment Pool } \\
\text { ( } N=134 \text { Clinicians) }\end{array}$ \\
\hline \multicolumn{3}{|l|}{ Practice setting } \\
\hline \multicolumn{3}{|l|}{ Public system } \\
\hline Clinics, No. & 11 & 15 \\
\hline Clinicians, No. (\%) & $20(69)$ & $88(66)$ \\
\hline \multicolumn{3}{|l|}{ University system } \\
\hline Clinics, No. & 5 & 5 \\
\hline Clinicians, No. (\%) & $9(31)$ & $46(34)$ \\
\hline \multicolumn{3}{|l|}{ Profession type, No. (\%) } \\
\hline Physician & $22(76)$ & $93(69)$ \\
\hline Nurse practitioner & $6(21)$ & $38(28)$ \\
\hline Physician assistant & $1(3)$ & $3(2)$ \\
\hline \multicolumn{3}{|l|}{ Specialty, No. (\%) } \\
\hline Family medicine & $13(45)$ & $59(44)$ \\
\hline Internal medicine & $10(34)$ & $52(39)$ \\
\hline Pediatrics & $6(21)$ & $23(17)$ \\
\hline $\begin{array}{l}\text { Time in clinical practice, } \\
\text { No. (\%) }\end{array}$ & & NA \\
\hline$<1$ year & $1(3)$ & \\
\hline $1-5$ years & $11(38)$ & \\
\hline$>5$ years & $17(59)$ & \\
\hline $\begin{array}{l}\text { Half-day patient care } \\
\text { sessions worked per } \\
\text { week, mean (range) }\end{array}$ & $4.8(2-8)$ & NA \\
\hline $\begin{array}{l}\text { Minutes per visit, mean } \\
\text { (range) }\end{array}$ & $23(12-30)$ & NA \\
\hline $\begin{array}{l}\text { Patients in panel, mean } \\
\text { (range) }\end{array}$ & $\begin{array}{l}680 \\
(100-1,600)\end{array}$ & NA \\
\hline \multicolumn{2}{|l|}{ Clinic SDH score, No. ${ }^{a}$} & NA \\
\hline 1 & 0 & \\
\hline 2 & 1 & \\
\hline 3 & 0 & \\
\hline 4 & 2 & \\
\hline 5 & 3 & \\
\hline 6 & 3 & \\
\hline 7 & 10 & \\
\hline 8 & 3 & \\
\hline 9 & 4 & \\
\hline 10 & 2 & \\
\hline \multicolumn{2}{|l|}{ Burnout risk $^{\mathrm{b}}$} & NA \\
\hline \multicolumn{3}{|l|}{ EE score, No. (\%) } \\
\hline Low & $6(21)$ & \\
\hline Average & $11(39)$ & \\
\hline High & $11(39)$ & \\
\hline \multicolumn{3}{|l|}{ DP score, No. (\%) } \\
\hline Low & $19(68)$ & \\
\hline Average & $6(21)$ & \\
\hline High & $3(11)$ & \\
\hline \multicolumn{3}{|c|}{$\begin{array}{l}\mathrm{EE}=\text { emotional exhaustion; } \mathrm{DP}=\text { depersonalization; } \mathrm{NA}=\text { data not available; } \mathrm{SDH}=\text { social } \\
\text { determinants of health. }\end{array}$} \\
\hline \multicolumn{3}{|c|}{$\begin{array}{l}\text { a Availability of resources to address social needs. Assessed from response to, "My clinic has } \\
\text { the resources, such as dedicated staff, community programs, resources or tools to address } \\
\text { patients' social needs," on a scale of } 1 \text { to } 10 \text { where higher score indicates greater agreement. } \\
\text { b Among } 28 \text { clinicians ( }(1 \text { clinician did not provide responses). EE: } 0-1 \text { for low, } 2-3 \text { for aver- } \\
\text { age, } 4-6 \text { for high (range, } 1-6) \text {. DP: } 0-1 \text { for low, } 2-3 \text { for average, } 4-6 \text { for high (range, } 0-5 \text { ). } \\
\text { Response options: } 0=\text { never, } 1=\text { a few times a year or less, } 2=\text { once a month or less, } 3=\text { a } \\
\text { few times a month, } 4=\text { once a week, } 5=\text { a few times a week, } 6=\text { every day. }{ }^{36}\end{array}$} \\
\hline
\end{tabular}



Burnout Risk ( $\mathrm{N}=28)$

\begin{tabular}{|c|c|c|}
\hline DP Score & Low to Average EE Score & High EE Score \\
\hline \multirow[t]{3}{*}{ Low to average } & 17 clinicians (SDH score: mean $=6.9$; range, 4-10) & 8 clinicians (SDH score: mean $=5.9 ;$ range, $2-9$ ) \\
\hline & $\begin{array}{l}\text { "We have a social worker, a care support team. I'm often ask- } \\
\text { ing people to make phone calls for me. I feel pretty certain } \\
\text { that they can do it. So, I feel good about the care that we } \\
\text { provide." (physician; average EE, low DP; SDH score = 10) }\end{array}$ & $\begin{array}{l}\text { "A lot of times there are things that you cannot help [patients] } \\
\text { with. Some of our patients already are homeless. We are } \\
\text { lucky enough to have a social worker, but what can she do? } \\
\text { I mean, regular people can't even afford to live in San Fran- } \\
\text { cisco." (physician; high EE, low DP; SDH score = 5) }\end{array}$ \\
\hline & $\begin{array}{l}\text { "I feel like [patients] have some responsibility in their own } \\
\text { health care. I can give them all the options in the world, } \\
\text { if they want to talk to a counselor or they want to go to a } \\
\text { group. But if they don't want to do any of the above, it's } \\
\text { not going to impact my ability to feel like whether I've } \\
\text { succeeded or not." (nurse practitioner; average EE, low DP; } \\
\text { SDH score = 8) }\end{array}$ & $\begin{array}{l}\text { cisco." (physician; high EE, low DP; SDH score = 5) } \\
\text { "Even if there is a behavioral health navigator, really, it all } \\
\text { kind of falls on you." (physician; high EE, average DP; SDH } \\
\text { score =6) }\end{array}$ \\
\hline \multirow[t]{3}{*}{ High } & \multirow[t]{3}{*}{ No clinicians in this category } & 3 clinicians (SDH score: mean $=7.3$; range, 6-9) \\
\hline & & $\begin{array}{l}\text { "Realistically, half or more of the illnesses that we see are } \\
\text { related to substance abuse, whether it's illicit drugs, alco- } \\
\text { hol, tobacco. If you throw in other social issues-homeless- } \\
\text { ness, immigration, stress of poverty in general-surely, well } \\
\text { over } 50 \% \text {. The inability to address those issues is a source } \\
\text { of frustration." (physician; high EE, high DP; SDH score = 7) }\end{array}$ \\
\hline & & $\begin{array}{l}\text { "Even with a nice behavior health system, through social } \\
\text { work and all that, I feel sometimes I'm helpless and power- } \\
\text { less to give [patients] more. Sure, I can sign my name on } \\
\text { and give them health services, but I don't feel sometimes } \\
\text { that's what they need." (physician; high EE, high DP; SDH } \\
\text { score = 9) }\end{array}$ \\
\hline
\end{tabular}

$\mathrm{DP}=$ depersonalization; $\mathrm{EE}=$ emotional exhaustion; $\mathrm{SDH}=$ social determinants of health

often than the group with low to average emotional exhaustion and low to average depersonalization and the group with high emotional exhaustion and high depersonalization. Finally, the 3 clinicians in the high emotional exhaustion and high depersonalization group expressed feeling a low sense of individual efficacy even in the presence of social resources.

The majority of themes did not, however, cluster by burnout phenotype. Across burnout levels, clinicians valued social needs interventions that were timely, accessible, tailored to patient circumstances, and sensitive to patient feedback. Clinicians in our sample also universally expressed some skepticism around referral-based interventions, largely related to concerns about whether these programs could affect patients' social needs. For example, one said, "We do have a lot of staff and at least referrals and resources. But is that really enough to address patients' needs? I'm not so sure." (physician, average emotional exhaustion,

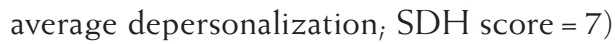

\section{Unmet Social Needs Influence Clinical Practice}

Most clinicians believed that addressing social needs is critical to providing high-quality primary care; however, despite wanting to address social needs, clinicians felt concerned that doing so would disrupt workflow. Clinicians felt inadequately trained to navigate resources and anticipated emotional discomfort and inefficacy with attempts to address social needs on their own. Additionally, several clinicians described situations wherein unmet social needs precipitated mental health crises. Managing these situations caused clinicians to fall behind, to expend other clinic staff and time on seeking resources for patients, and to often feel ineffective, as exemplified by this statement:

That's a daily source of frustration, you have a patient who is in crisis, and now the [patient] has to call their 1-800 number to find [help]... We couldn't get [the care] fast enough, integrated enough...We easily spent 10 hours a week just trying to do this. On 1 patient. (physician; average emotional exhaustion, average depersonalization; $\mathrm{SDH}_{\text {score }}=4$ )

Unmet social needs also interfered with conventional medical recommendations. Clinicians expressed frustration and questioned the effectiveness of their treatment plans when the social context of patients' lives remained unaddressed, for example, trying to control diabetes when patients had poor access to healthy foods. Moreover, unmet social needs made clinicians feel frustrated and disconnected from patients:

I've had situations where people come in and tell me they're going to be evicted from their house the next day, and I'm coming in like, 'So, how many fruits and vegetables did you eat this week?' ... It just feels... like we're failing very often. (nurse practitioner, average emotional exhaustion, low depersonalization; SDH score $=7$ ) 
In the absence of social needs resources, clinicians described a negative cycle whereby inefficacy exacerbated emotional exhaustion and vice versa. Having to reconcile the responsibility they felt to their patients with their limited capacity to facilitate access to social services was emotionally taxing. In turn, being emotionally exhausted made clinicians feel less capable of addressing social needs, as is evident from this comment:

It plays on your sympathy to hear how difficult people's lives are, the frustration of being limited in what you can do, especially when [patients] are looking to you as the person who maybe can do something about it. (physician, high emotional exhaustion, high depersonalization, $\mathrm{SDH}$ score $=7$ )

\section{Embedded Social Needs Resources Buffer Against Burnout}

Clinicians described how embedded or colocated services such as behavioral health, social work, and eligibility assistance offered multiple benefits, including services that exceeded basic referrals to external social services

They also valued the expertise that staff dedicated to addressing social needs brought to their clinics. They perceived that social and behavioral staff made clinical practice more efficient and effective, and could help leverage valuable resources outside of clinic for their patients:

I couldn't personally do the legwork to figure out what [patients] need, figure out what they qualify for... Trying to do geriatric outpatient work without a social worker would be unmanageable. (physician; average emotional exhaustion, low depersonalization, $\mathrm{SDH}_{\text {score }}=8$ )

Dedicated staff also directly contributed to clinicians' sense of efficacy by allowing them to focus on their medical and care coordination roles. Colocated colleagues eased the burden of clinicians feeling solely responsible for the patient, and thus mitigated burnout, as one noted:

[Having social services] is a huge relief. It makes me feel like I don't have to worry about the bigger picture on my own. I can say, I'm your primary medical provider. I'm not a psychiatrist. I'm not a social worker, but I can get that care for you. (nurse practitioner; average emotional exhaustion, low depersonalization; SDH score $=9$ )

Most clinicians noted that when patients' social needs were effectively met, their own morale improved. Examples included successfully negotiating a discount on a patient's utilities bill, getting a citizenship examination waived, and connecting patients to Supplemental Nutritional Assistance Program benefits. As one clinician stated:
When you're successful, you feel great. It's like all your work was worth something. Just the fact that I pointed [patients] in that direction. Realistically, it's probably going to have a much better impact on their overall well-being than me giving them a medicine. (physician; average emotional exhaustion, low depersonalization; $\mathrm{SDH}$ score $=7$ )

\section{Clinic-Level Social Needs Resources Are Necessary But Insufficient to Address Burnout}

Almost all clinicians described multiple sources for symptoms of burnout. They anticipated that even if social resources were maximized at the clinic level (absent other interventions), some level of burnout would persist. Notably, a subset of 4 participants were at high risk of emotional exhaustion despite reporting SDH scores in the top third of our sample. These participants described dissatisfaction with their electronic health records systems and personal factors such as competing family responsibilities as key contributors to their burnout. Other reported causes of burnout included overwhelming workloads, inadequate clinical staffing, and documentation and regulatory requirements.

Clinicians further specified that broader structural changes, both within and outside the health system, are needed in concert with clinic-level social needs resources. For example, reimbursement should reflect the time and energy spent working with patients with social needs:

It's not like I'm getting paid any differently from Medicare to take care of somebody that's homeless with diabetes versus somebody that is diabetic and has a house. It makes it difficult to feel supported from our health care system. (physician; $_{i}$ high emotional exhaustion, low depersonalization; $\mathrm{SDH}$ score $=4$ )

Clinicians noted that even if and when primary care clinics maximized the internal capacity to address social needs, external, nonclinical social, governmental, and community resources are required to really improve SDH and reduce patients' social needs; one noted, "The help that we can provide only goes so far or is only so much, and there's so much more to be done" (nurse practitioner, average emotional exhaustion, low depersonalization; SDH score $=7$ ).

External resources were often perceived as difficult to access amid limited resources, restrictive eligibility requirements, staff turnover, or unstable funding. For example, clinicians expressed feeling hopeless when patients were placed on housing wait lists that were years long, or when caseworkers moved to other jobs. Clinicians also noted the lack of clarity and consistency around community caseworkers' roles and expressed interest in better communication between health care and social care professionals. 


\section{DISCUSSION}

In this study conducted in urban clinics serving lowincome patients, primary care clinicians described 3 main pathways linking burnout and clinic capacity to address patient social needs. First, unmet social needs prevented clinicians from effectively and efficiently providing medical and mental health care. Second, colocated medical and social services protected against burnout by emotionally supporting clinicians and restoring their more medical roles. Third, health system and community-level structural barriers to addressing patients' social needs exacerbated burnout.

Our findings suggest that increasing social needs resources may mitigate burnout symptoms. These interventions are likely to be more effective at decreasing burnout when implemented alongside other burnout-prevention initiatives. ${ }^{37,38}$ The potential for increased social needs resources to increase individual clinicians' professional efficacy may vary by clinicians' baseline burnout phenotype and should be the focus of future research. Clinicians with high emotional exhaustion and depersonalization scores may feel less equipped to address patients' social needs. Additional supports may need to be directed at clinicians experiencing these burnout symptoms.

Our study findings also help to explain other recent work linking burnout and capacity to address social needs. ${ }^{22,24-26}$ Having dedicated team members directly address social needs helped clinicians stay engaged and feel more connected with their patients, which is a major source of work-related satisfaction for clinicians. ${ }^{39,40}$ The findings also highlight how structural challenges_-including lack of reimbursement, inadequate integration between medical and social delivery systems, and insufficient nonclinical capacity to address social needs - presented key barriers to professional efficacy, an important component of burnout. ${ }^{41}$

These findings could be interpreted to reveal a potential conflict between clinicians' desire to increase the capacity to address social needs in primary care and their competing workload demands. More social needs-related activities could potentially worsen burnout by increasing time spent coordinating care, which has been associated with greater clinician stress. ${ }^{42}$ In our interviews, however, clinicians emphasized that a team-based approach to addressing social needs, not one that depended on clinicians, would best enable action on patients' social needs. Previous work suggests that this approach is particularly effective at decreasing stress if clinicians are satisfied with the help received. ${ }^{42} \mathrm{~A}$ team-based approach may also make social needs activities more scalable, consistent with other literature suggesting an important feature of high-performing, innovative primary care is expansion of the health care team. ${ }^{43}$

Our findings are based on interviews with a limited number of salaried clinicians serving low-income populations in a single urban area and may not be generalizable. We also did not collect clinic-level measures of available social needs resources, or more comprehensive indicators of burnout levels. Our sample included only 3 clinicians scoring high on both depersonalization and emotional exhaustion, future work with larger samples should explore the unique perspectives of this group.

This exploratory study may inform efforts to improve social needs capacity in primary care ${ }^{44-47}$ and initiatives targeted to reduce primary care clinician burnout symptoms. ${ }^{48}$ Primary care residents are deterred from continuing primary care practice by frustration with navigating the boundary between social and medical needs, ${ }^{49}$ and trainees increasingly seek additional avenues for intervention. ${ }^{50}$ Clinicians change care plans and report improved patient interactions when they are aware of social needs..$^{51}$ Equipping clinicians with social needs resources through teambased care may therefore improve the sustainability and effectiveness of primary care work. Given that research on burnout interventions has demonstrated only modest effects for those that do not consider patients' social needs, ${ }^{20,21,52-54}$ increasing clinics' capacity to address social needs may be a burnout prevention strategy worth testing.

To read or post commentaries in response to this article, see it online at http://www.AnnFamMed.org/content/17/6/487.

Submitted August 25, 2018; submitted, revised, May 10, 2019; accepted May 30, 2019.

Key words: burnout; job satisfaction; professional practice; social determinants of health; social medicine; vulnerable populations; psychosocial support systems; personalized care; primary care; practice-based research

Funding support: This research project was made possible with funding from the University of California Berkeley-University of California San Francisco Joint Medical Program Thesis Research Grant and Schoeneman Summer Stipend, and from the Albany Medical College Summer Fellowship Program. Dr Gottlieb's work on this project was supported by a grant from Kaiser Permanente.

Acknowledgments: A.K. acknowledges her Joint Medical Program thesis working group for their comments on an early draft of this article. The study team would also like to thank the reviewers for their constructive comments, which helped clarify and improve the article.

Disclaimer: The views expressed are solely those of the authors and do not necessarily represent official views of the authors' affiliated institutions or funders.

Supplemental materials: Available at http://www.AnnFamMed. org/content/17/6/487/suppl/DC1/. 


\section{References}

1. Shanafelt TD, Hasan O, Dyrbye LN, et al. Changes in burnout and satisfaction with work-life balance in physicians and the general US working population between 2011 and 2014. Mayo Clin Proc. 2015; 90(12):1600-1613.

2. Shanafelt TD, Dyrbye LN, West CP, Sinsky CA. Potential impact of burnout on the US physician workforce. Mayo Clin Proc. 2016;91(11): 1667-1668.

3. Rotenstein LS, Torre M, Ramos MA, et al. Prevalence of burnout among physicians: a systematic review. JAMA. 2018;320(11): 1131-1150.

4. Shanafelt TD, West CP, Sinsky C, et al. Changes in burnout and satisfaction with work-life integration in physicians and the general US working population between 2011 and 2017. Mayo Clin Proc. 2019; 94(9):1681-1694.

5. Ahola K, Hakanen J, Perhoniemi R, Mutanen P. Relationship between burnout and depressive symptoms: a study using the person-centred approach. Burn Res. 2014;1(1):29-37.

6. Dewa CS, Loong D, Bonato S, Thanh NX, Jacobs P. How does burnout affect physician productivity? A systematic literature review. BMC Health Serv Res. 2014;14(1):325.

7. Shanafelt TD, Mungo M, Schmitgen J, et al. Longitudinal study evaluating the association between physician burnout and changes in professional work effort. Mayo Clin Proc. 2016;91(4):422-431.

8. Rabatin J, Williams E, Baier Manwell L, Schwartz MD, Brown RL, Linzer M. Predictors and outcomes of burnout in primary care physicians. J Prim Care Community Health. 2016;7(1):41-43.

9. Sinsky CA, Dyrbye LN, West CP, Satele D, Tutty M, Shanafelt TD. Professional satisfaction and the career plans of US physicians. Mayo Clin Proc. 2017;92(11):1625-1635.

10. Hamidi MS, Bohman B, Sandborg C, et al. Estimating institutional physician turnover attributable to self-reported burnout and associated financial burden: a case study. BMC Health Serv Res. 2018; 18(1):851.

11. Willard-Grace R, Knox M, Huang B, Hammer H, Kivlahan C, Grumbach K. Burnout and health care workforce turnover. Ann Fam Med. 2019;17(1):36-41.

12. Schutte $L$ What you don't know can cost you: building a business case for recruitment and retention best practices. Journal of ASPR, Summer 2012. http://www.aspr.org/?696. Published 2012. Accessed May 4, 2018.

13. Salyers MP, Bonfils KA, Luther $L$, et al. The relationship between professional burnout and quality and safety in healthcare: a metaanalysis. J Gen Intern Med. 2017;32(4):475-482.

14. Hayashi AS, Selia E, McDonnell K. Stress and provider retention in underserved communities. J Health Care Poor Underserved. 2009; 20(3):597-604.

15. Friedberg MW, Reid RO, Timbie JW, et al. Federally qualified health center clinicians and staff increasingly dissatisfied with workplace conditions. Health Aff (Millwood). 2017;36(8):1469-1475.

16. Garg A, Jack B, Zuckerman B. Addressing the social determinants of health within the patient-centered medical home: lessons from pediatrics. JAMA. 2013;309(19):2001-2002.

17. Shanafelt TD, Boone $S$, Tan $L$, et al. Burnout and satisfaction with work-life balance among US physicians relative to the general US population. Arch Intern Med. 2012;172(18):1377-1385.

18. Dyrbye LN, Varkey P, Boone SL, Satele DV, Sloan JA, Shanafelt TD. Physician satisfaction and burnout at different career stages. Mayo Clin Proc. 2013;88(12):1358-1367.

19. West CP, Dyrbye LN, Shanafelt TD. Physician burnout: contributors, consequences and solutions. J Intern Med. 2018;283(6):516-529.

20. West $C_{1}$, Dyrbye LN, Erwin PJ, Shanafelt TD. Interventions to prevent and reduce physician burnout: a systematic review and metaanalysis. Lancet. 2016;388(10057):2272-2281.
21. Panagioti $M$, Panagopoulou $E$, Bower $P$, et al. Controlled interventions to reduce burnout in physicians. JAMA Intern Med. 2017; 177(2):195-205.

22. Weiner JZ, McCloskey JK, Uratsu CS, Grant RW. Primary care physician stress driven by social and financial needs of complex patients. J Gen Intern Med. 2019;34(6):818-819.

23. Whitebird RR, Solberg LI, Crain AL, et al. Clinician burnout and satisfaction with resources in caring for complex patients. Gen Hosp Psychiatry. 2017:44:91-95.

24. Pantell MS, De Marchis E, Bueno A, Gottlieb LM. Practice capacity to address patients' social needs and physician satisfaction and perceived quality of care. Ann Fam Med. 2019;17(1):42-45.

25. Olayiwola JN, Willard-Grace R, Dubé K, et al. Higher perceived clinic capacity to address patients ' social needs associated with lower burnout in primary care providers. J Health Care Poor Underserved. 2018;29(1):415-429.

26. De Marchis E, Knox M, Hessler $D$, et al. Physician burnout and higher clinic capacity to address patients' social needs. J Am Board Fam Med. 2019;32(1):69-78.

27. Charmaz K. The logic of grounded theory coding practices and initial coding. In: Constructing Grounded Theory. 2nd ed. Thousand Oaks, CA: Sage Publications Ltd; 2014:109-137.

28. Charmaz K. Crafting and conducting intensive interviews. In: Constructing Grounded Theory. 2nd ed. Thousand Oaks, CA: Sage Publications Ltd; 2014:55-82.

29. Maxwell JA. Validity: How might you be wrong? In: Qualitative Research Design: An Interactive Approach. 3rd ed. Thousand Oaks, CA: Sage Publications Inc; 2013:121-138.

30. Willard-Grace R, Hessler D, Rogers E, Dubé K, Bodenheimer T, Grumbach K. Team structure and culture are associated with lower burnout in primary care. J Am Board Fam Med. 2014;27(2):229-238.

31. Sheehan KB. E-mail survey response rates: a review. J Comput Commun. 2001;6(2)

32. West CP, Dyrbye LN, Satele DV, Sloan JA, Shanafelt TD. Concurrent validity of single-item measures of emotional exhaustion and depersonalization in burnout assessment. J Gen Intern Med. 2012;27(11): 1445-1452.

33. Dedoose, version D.7.0.23. Web application for managing, analyzing, and presenting qualitative and mixed method research data. Los Angeles, CA: SocioCultural Research Consultants, LLC; 2016. http://www.dedoose.com. Accessed May 4, 2018.

34. Miles MB, Huberman AM. Saldaña J. Fundamentals of qualitative data analysis. In: Qualitative Data Analysis: A Methods Sourcebook. 3rd ed. Thousand Oaks, CA: Sage Publications Ltd; 2013:69-104.

35. Glaser BB, Strauss AL. The Discovery of Grounded Theory: Strategies for Qualitative Research. Chicago, IL: Aldine; 1967.

36. West CP, Dyrbye LN, Sloan JA, Shanafelt TD. Single item measures of emotional exhaustion and depersonalization are useful for assessing burnout in medical professionals. J Gen Intern Med. 2009;24(12):1318-1321.

37. Dyrbye LN, Trockel M, Frank E, et al. Development of a research agenda to identify evidence-based strategies to improve physician wellness and reduce burnout. Ann Intern Med. 2017;166(10): 743-744.

38. Swensen SJ, Shanafelt T. An organizational framework to reduce professional burnout and bring back joy in practice. Jt Comm I Qual Patient Saf. 2017;43(6):308-313.

39. The Physicians Foundation. 2016 Survey of America's Physicians: Practice Patterns \& Perspectives. https://physiciansfoundation.org/ wp-content/uploads/2017/12/Biennial_Physician_Survey_2016.pdf. 2016. Accessed May 4, 2018.

40. Shanafelt TD. Enhancing meaning in work: a prescription for preventing physician burnout and promoting patient-centered care. JAMA. 2009;302(12):1338-1340. 
41. Leiter MP, Maslach C. Latent burnout profiles: A new approach to understanding the burnout experience. Burn Res. 2016;3(4):89-100.

42. Okunogbe A, Meredith LS, Chang ET, Simon A, Stockdale SE, Rubenstein LV. Care coordination and provider stress in primary care management of high-risk patients. J Gen Intern Med. 2018; 33(1):65-71.

43. Wagner EH, Flinter M, Hsu C, et al. Effective team-based primary care: observations from innovative practices. BMC Fam Pract. 2017; 18(1):13.

44. Luchenski S, Maguire N, Aldridge RW, et al. What works in inclusion health: overview of effective interventions for marginalised and excluded populations. Lancet. 2018;391(10117):266-280.

45. Robert Wood Johnson Foundation. Paying for Population Health: Case Studies on the Health System's Role in Addressing Social Determinants of Health. https://www.academyhealth.org/sites/ default/files/Paying_for_Pop_Health_Case_Studies_Full_Jan2018. pdf. 2018. Accessed Oct 20, 2019.

46. Onie RD, Lavizzo-Mourey R, Lee TH, Marks JS, Perla RJ, Case HCAT. Integrating social needs into health care: a twenty-year case study of adaptation and diffusion. Health Aff (Millwood). 2018;37(2): 240-247.

47. Pescheny JV, Pappas Y, Randhawa G. Facilitators and barriers of implementing and delivering social prescribing services: a systematic review. BMC Health Serv Res. 2018;18(1):86.
48. Shanafelt TD, Dyrbye LN, West CP. Addressing physician burnout: the way forward. JAMA. 2017;317(9):901-902.

49. Long T, Chaiyachati K, Bosu O, et al. Why aren't more primary care residents going into primary care? A qualitative study. J Gen Intern Med. 2016;31(12):1452-1459.

50. Eisenstein L. To fight burnout, organize. N Engl J Med. 2018;379(6): 509-511.

51. Tong ST, Liaw WR, Kashiri PL, et al. Clinician experiences with screening for social needs in primary care. J Am Board Fam Med. 2018;31(3):351-363

52. Reid RJ, Coleman K, Johnson EA, et al. The Group Health medical home at year two: cost savings, higher patient satisfaction, and less burnout for providers. Health Aff (Millwood). 2010;29(5):835-843.

53. Linzer M, Poplau S, Grossman E, et al. A cluster randomized trial of interventions to improve work conditions and clinician burnout in primary care: results from the Healthy Work Place (HWP) Study. J Gen Intern Med. 2015;30(8):1105-1111.

54. Meredith LS, Schmidt Hackbarth N, Darling J, et al. Emotional exhaustion in primary care during early implementation of the VA's medical home transformation: Patient-aligned Care Team (PACT). Med Care. 2015;53(3):253-260.

\title{
๑.० Register by December 30, 2019 and save \$75! •.०
}

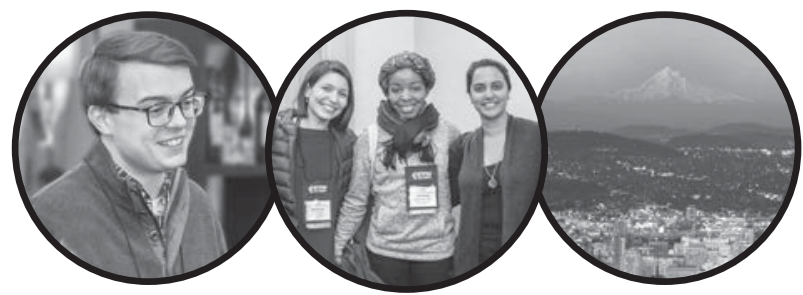

\section{- REGISTRATION IS OPEN!

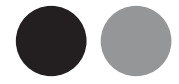 \\ 2020 STFM Conference on Medical Student Education}

\author{
Get connected! Acquire the skills and tools you need to prepare your medical \\ students to lead and prosper in a new environment of patient care.
}

January 30-February 2, $2020 \bullet$ Portland Marriott Downtown Waterfront • Portland, Oregon

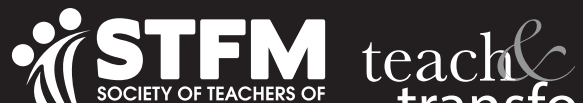 transform}

\section{Register today at stfm.org/mse/register}

